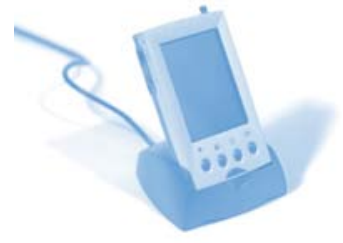

Graham Wightman
School of Contemporary
Sciences
University of Abertay
Dundee
DD1 1HG
g.wightman@abertay.ac.uk

Audio recording of lectures by students or staff is increasing, and the availability of facilities for recording and of portable audio equipment for playback can make this an attractive prospect.

\section{Recording of lectures}

\begin{abstract}
In recent years there has been an increase in the number of students wanting to record lectures. Two factors have contributed to this. Firstly, there is wide availability of compact, solid state recorders, and recorders are often incorporated into other goods (MP3 players, mobile phones, cameras, laptops). Secondly, within many universities facilities have been provided by student support services for students with a special need to record lectures.
\end{abstract}

However, the recording of lectures presents a number of issues related to ownership, data protection, potential misuse, and the pedagogic issue of ensuring equal treatment for all students. University recording policies address some of these issues, but the individual academic also needs to reflect on the consequences for their teaching.

A trial has been carried out offering streamed recordings of lectures, and the merits of streaming and downloading are discussed. A survey was made on the usage by students and their reasons for accessing the recordings, and these are reported. There have been a number of advantages to students as well as to the lecturer which have required relatively little extra burden on the lecturer. One important initial conclusion appears to be the need to incorporate recordings as part of the teaching material in the initial pedagogic design rather than an addition. For some students the recordings have proved a valuable additional resource and feedback from students has been positive.

\section{Introduction}

Audio recording of lectures by students or staff is increasing, and the availability of facilities for recording and of portable audio equipment for playback can make this an attractive prospect. There are, however, a number of considerations that need to be addressed before embarking on an exercise to make lectures available in audio format. This paper discusses some of these and presents some evidence of their benefit to students. The role of recording can be extended to video recording, preparation of support materials for tutorials or revision and verbal feedback. However, this discussion focuses on recording live lectures since audio recording require little additional input from staff yet provide a useful extra resource for students.

\section{Issues for Consideration}

The recording of lectures presents some serious ethical and legal issues. The intention in allowing special-need students to record lectures is to provide lecture material in a form that is a reasonable adjustment (SENDA 2001) ${ }^{1}$. However, in doing so it could be argued that we are disadvantaging students without a special need, since they have only a single opportunity to hear the lecture. This issue is not unique to recording, and is a pedagogic issue that has to be addressed with care. Making a recording that is available to all students can benefit certain learning styles as well as those with disabilities. In fact the Higher Education Academy (HEA) ${ }^{2}$ recommends audio recording as a tool to aid international students. A web search will show other examples of students wanting to record lectures ${ }^{3}$, or of manufacturers advocating their product for this purpose ${ }^{4}$.

From the point of view of the academic (and of the university) there is the question of copyright of material. Academic contracts usually clarify ownership of materials produced for teaching purpose. However, in the case of recordings of a live lecture the issue may be complicated by the ownership of the original live 'performance' and ownership of the 'recording'. With current computing and internet facilities, it is very easy for recorded lecture material to be copied and made widely available. From a technical point of view, a student could even record the whole of their degree course and publish it and the institution or academic would then have to pursue action for any consequential loss. In these circumstances ownership of the recording may depend on whether the recording 
was made with or without permission, and what permissions were given for use of the recording. Most institutions now have a recording policy clarifying these issues and the main power is as a deterrent against misuse, but the onus would be on the institution or the academic to take action on any infringement.

Data protection is another aspect of recording. Again, contracts for staff will clarify what an institution expects from their employees, but students are in a different position. Whilst students normally sign a global waiver of some of their data protection rights (e.g. to allow for publication of graduation results) this waiver may not cover their rights if asking a question in class, and distribution of a recording where the voice of a student is also recorded might contravene this aspect of the law. Recording policies usually require a class to be informed when a recording is being made, but this could mean that the student's only option is not to ask the question unless the academic pauses the recording.

From an academic's point of view there may be a fear of the lecturer being replaced by a recording. On the other hand, offering additional resources can enhance a lecturer's reputation as a good teacher. A second concern in making recordings available is that it might mean a drop in class attendance. However, a counter-argument could be made that properly integrating recordings into the pedagogic design might improve engagement and hence increase attendance. Studies that have been carried out with video recordings of lectures (e.g. ${ }^{5-7}$ ) suggest that the effect on attendance is small, and similar results were observed in this present study.

A final aspect of recordings is their use, or misuse, for purposes not originally intended. Comments made by a lecturer could be taken out of context and broadcast maliciously (for example, a comment originally intended to provoke a student response). Video clips of school teachers have been circulated on You-Tube and other similar sites, and in May 2008 there was concern over a lecturer recorded advising students to fill in a questionnaire in order (allegedly) to bias the result. No-one would condone inappropriate action by staff, but should an audio recording originally made for one purpose be used as a tool to bring about disciplinary or legal action, particularly if the recording itself was made illicitly? There is clearly an ethical issue in the use of a recording and whilst the Data Protection Act may give some protection to staff, there is a possible grey area.

In summary, the issues that need to be addressed before considering recording lectures are:

- Equal treatment of all students.

- Ownership and copyright of content.

- Staff perceptions.

- Data protection for students.

- Misuse of recordings, or phrases taken out of context

\section{Recording Policies}

In view of these concerns many institutions have a recording policy and some examples can be found in the references ${ }^{8-10}$. These may allow any student to make recordings, but are more frequently concerned with special-needs students. Permission is usually granted for personal use within a limited time frame, provided prior agreement is obtained from all present (both staff and students). However, special-needs students can usually obtain a permission that overrules the need to obtain prior agreement, provided that everyone present is informed that a recording is being made. The onus is normally on the academic to inform the class that a recording is being made, but this can present confidentiality issues with the disability, if not correctly handled.

A policy makes clear to students the limits of acceptable behaviour. However, its main strength is as a deterrent against misuse by making it clear what action could be taken if a breach is incurred. In practice, applying these sanctions after serious misuse would probably be ineffective.

\section{A Trial in Recording Lectures}

Although I had tried experimenting with a tape recording of lectures in the late 90's, my experience of recordings by students began in sessions 2006-7 and 2007-8 when a small number of students with dyslexia asked to make recordings. In 2006-7 one person asked to record a single lecture, but in 2007-8 three students asked about recording a lecture series, and initially this meant three separate recorders being worn or placed on the desk. Subsequently two of these students decided to record from their own desk. During this lecture series it became unclear whether other students were taking advantage of recording and were also using other recording devices without permission. The class were reminded of the university recording policy, but it still remained unclear whether recordings were being made.

The current generation of students has grown up in an environment where recording is not seen as particularly immoral, and CDs are copied and files downloaded with little concern over copyright.

One alternative is to produce a single official recording. Abertay's Information Services were keen to support and encourage academic staff to use technology in support of teaching, so a trial of audio recording was carried out.

\section{Initial Objectives and Potential Pitfalls}

There were several reasons why I thought audio recordings of live lectures might offer potential benefits:

- An official recording allows some control in the use of the product rather than students producing their own (multiple) versions.

- There is value in all students having the opportunity to listen again for revision purposes.

- Sometimes students miss a lecture for valid reasons, and a recording could be beneficial in catching up on missed material.

- Recording might allow supplements to lectures, for example: provision of study material to cover the absence of the lecturer, and additional explanations if the original lecture required it.

I did, however, have some reservations:

- Would recordings increase the workload, or conversely would they reduce the need for academic staff?

- Ownership of the recording if students were able to download the sound file.

- Would the availability of recordings deter student attendance? 
It soon became apparent that a recording is not a substitute for the original. There is a debate in the literature ${ }^{5-7}$ on the value of recordings for students (mainly referring to audio-visual recording), but there appears to be consensus that recordings are not an adequate replacement for personal tuition. The audio recording is primarily a medium for transferring information but the majority of students still need to reflect on this information and will require additional support in order to convert it into knowledge that they can apply.

The issue of the additional workload proved to be a pleasant surprise and little extra time was involved. Initially Information Services provided support to download, edit and stream the files. Later on downloading and any editing were done by the lecturer. After careful consideration it was decided that ownership and availability would best be controlled by allowing the recordings to be accessed only as streamed files.
The decision to use streamed files rather than downloadable files raises a major consideration over access, since it restricts student ability to listen to the recording at a pc. A podcast in MP3 or WAV format, on the other hand, could be listened to anywhere. Streaming therefore gives some control over use and ownership of the recording (whilst a secondary recording could still be made from a streamed file by a student, it is more difficult and lower quality). However, there is also an important educational benefit: to listen to a streamed recording the student has to make a deliberate effort and set aside time and is therefore more likely to concentrate on the content. With a podcast the student may have the recording on in the background whilst undertaking other activities (multitasking) and not fully concentrate on the lecture. It also means that if a student misses a lecture they still have to set aside an hour to make it up - a recording is not an easy option to replace attendance at the lecture.

\section{Practical Aspects}

An Olympus digital voice recorder with clip-on microphone was used and provided adequate recordings on the low quality setting. The unit was portable and simple to use and the only requirement was remembering to switch on and off! This particular recorder did, however, require special software to download files. The class was warned at the start of each lecture that recording was about to begin. One benefit of a clip-on microphone is that it will not easily pick up student questions, thus minimising data protection issues. However, it does mean that it is necessary to repeat the question for the benefit of listeners to the recording

Editing was done using Audacity open-source freeware. Limited editing only was carried out to tidy up the start and finish, and to remove silences when students are writing. Some students, however, said they preferred the periods of silence to allow them time to consider what they had heard and to relate it to the PowerPoint slide, suggesting that for some students synthesis was taking place during their listening as they integrated information. Occasionally an irrelevant aside has been removed, but the editing was not essential and raw recordings have been made available. Summary notes could be scripted and recorded for revision purposes, but would take more time to prepare and is another area for future investigation. Recording live lectures minimises the input required and retains the naturalness of personal tuition.
Lectures accessed

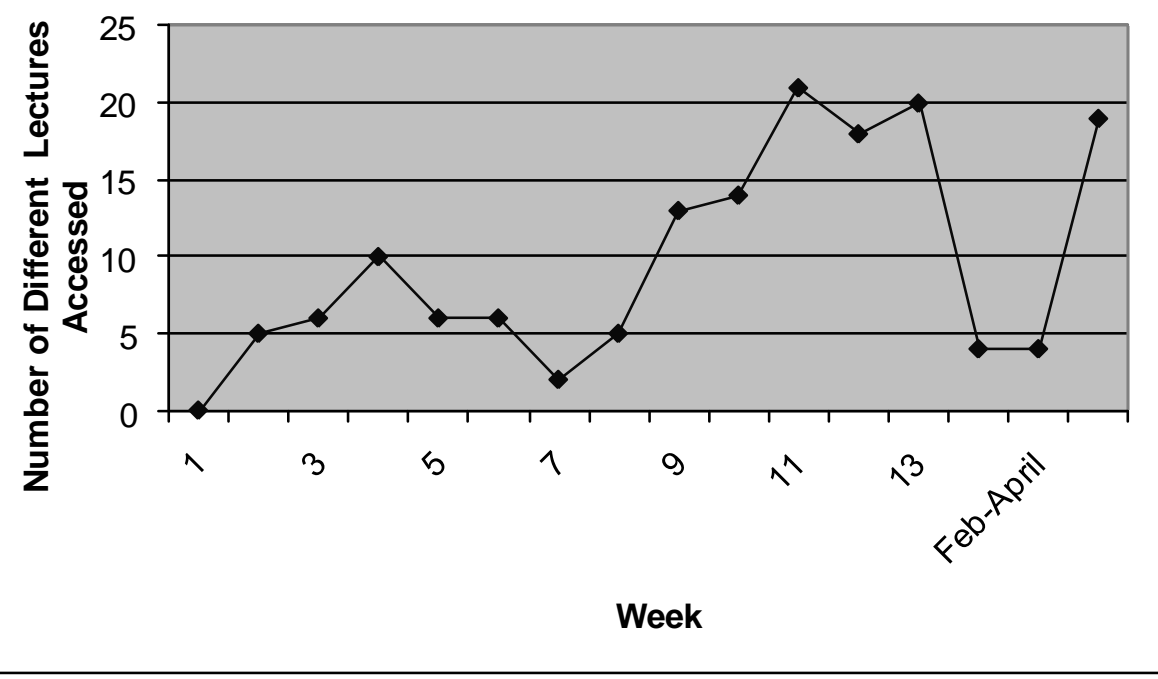

Figure 1: Accessions to the recording each week, Year 2 module.(Delay in streaming occurred weeks 5-7. Exam is week 13 and resit exam in August).

Streamed recordings can be accessed at any point in the recording so a student can select part of a lecture if they wish. One minor limitation of streamed recordings is the inability to vary the speed. Audio files can often be speeded up electronically by software that compresses the sound into shorter intervals, thus avoiding any change in pitch. This was briefly investigated, but my personal perception was that, whilst listening to speeded up versions of lectures did reduce the listening time it became difficult to assimilate the information once the speed was increased by $50 \%$, and this would reduce an hour's lecture by only 20 minutes. Whilst this might be attractive for revision purposes, it is an area that would need further investigation. 
When streaming files, consideration needs to be given to the distribution platform. Initially access was via hyperlinks but this presented problems for some students depending on their browser settings. The use of WebCT or Blackboard as a platform overcame this problem and gave the facility to see how frequently the files were used.

\section{Perceived Benefits}

The first benefit was actually an unexpected one. Listening to myself on a recording I became aware of mannerisms that the students were only too aware of! It has required a conscious effort to try and improve my delivery style, and this has been beneficial.

Students have used the recordings. Initially numbers were not high, but those who accessed the files were positive about the benefits, and the trial was continued and extended.
The ability to edit the files before transmission is a benefit where an area is lacking in clarity, or something was said that could be misunderstood. So far the only limited editing has been necessary. The delivery of one lecture had to be truncated, and it was possible to record a summary of additional points that had not been covered.

\section{Usage}

Initially the trial was limited to one part of a module, and access to the recordings was on request and was therefore not straight forward. Despite this, $20 \%$ of the cohort persevered, and their anecdotal evidence on the benefits was encouraging.

In the extended trial all lectures were made available covering part of a first year module, the whole of a second year module, and parts of a third and a fourth year module. In all cases access was through WebCT and recordings were usually available within a week, although for one three week period there was a delay in availability and this had an effect on usage. It needs to be recognised that accessing the link does not necessarily mean the whole, or even part, of the lecture was listened to. However, students repeatedly accessed the files, suggesting they were listening to them.

Level 4 students barely referred to the recordings until they started revision for exams (4 hits during the lecture period, with an additional 30 hits prior to exams, from a cohort of 30 out of a sequence of 7 lectures). This trend was also reflected in their use of other on-line support material. A similar effect was observed on two third year modules taught by multiple staff (23 hits during lectures with 17

Figure 2: Range of lectures accessed each week.

Observations on student use are discussed in more detail in the next section.

The library of recordings is a resource that students can be referred to if they require additional help.

The recordings have been used by absent students as well as students with disabilities, and a range of students have accessed them for revision purposes.

The recording can be used to check exactly what was said on a particular topic, by both staff and by students. This has been beneficial when students have sought verbal clarification of assessments. further hits during revision for a cohort of 44 and 12 lectures, and 10 hits during lectures and 68 during revision for a cohort of 44 and 14 lectures). In both cases students accessed pre-lab PowerPoint presentations and material in support of coursework (50\% hit rate). This suggests that access through technology is not the limiting factor, but their perception of the benefit of the recordings may be. Use for revision purposes does seem to be attractive. The first year module again is part of a multiple-taught module and 113 hits were made from a cohort of 82 students and 7 lectures. (In this module there was no examination so no differentiation in use has been made). 
Table 1: Ratio of total hits to cohort numbers and lecture numbers.

\begin{tabular}{|c|c|c|c|c|}
\hline Cohort & Total Hits & Number of Lectures & Number in cohort & Ratio \\
\hline Year 4 & 34 & 7 & 30 & $16.2 \%$ \\
\hline Year 3 & 40 & 12 & 44 & $7.5 \%$ \\
\hline Year 3 & 78 & 14 & 44 & $12.6 \%$ \\
\hline Year 2 & 449 & 31 & 62 & $23.4 \%$ \\
\hline Year 1 & 113 & 7 & 82 & $19.7 \%$ \\
\hline
\end{tabular}

The second year module was taught by a single lecturer. Out of a cohort of 62 , and 31 lectures a total of 449 hits were made. 8 recordings received over 10 hits during the first 6 weeks, with two recordings (the introduction to the module and a lab feedback/prelab tutorial) receiving 28 and 32 hits. However, usage declined during the 3 week period when there was a delay in uploading recordings, as seen in Figure 1. Figure 2 shows that about $66 \%$ of the recordings were being accessed in the three week period prior to the exam and the period prior to the resit. 16 students had over 10 hits each (and 3 students had over 30 hits) whilst 21 students had no hit or a single hit. Students with multiple hits are more likely to have listened to at least part of the recording whereas a single hit may mean only one item was of interest, or it may mean the student listened but decided the resource was not helpful to them. An analysis of hits and absences also showed that students were using this as a resource to make good missed lectures. The use of recordings was plotted against attendance and against module grade and these graphs showed that use was made both by students who attended regularly and students with poor attendance. Similarly some students who obtained good grades made extensive use of this additional resource and some weaker students also appreciated the additional support. Likewise, there was a spread of non-users across all attendees and all abilities. It therefore appears that the resource is of potential benefit to all students and it is a personal choice whether to use it.
I had wondered whether first and second year students may be more inclined to use additional web-based support resources than later year students: level 3 and level 4 students should be accessing their own support resources and consequently may prefer to look at other sources rather than listening again to the lecture. The ratio (hits/(students $x$ lectures)) is shown in Table 1. This ratio indicates the uptake and if every student accessed each lecture once, it would give a value of $100 \%$. However, the ratio does not take into account multiple uses by the same student, nor does it differentiate use during revision periods. Table 1 does show a higher ratio for year 1 and 2 . The level 2 cohort had the highest ratio (23.4\%) and in this module WebCT was used extensively as a source of support material and students had to download and submit practical worksheets each week, and it is thought that this integration and familiarity has increased the use of recordings. The decline in usage due to the three week delay in uploading recordings (Figure 1) may also add support for familiarity of access being important, but further work is needed to confirm this.

\section{Student Feedback}

Initial feedback from students was via verbal comments and was always positive. However, students may be less likely to comment adversely to a member of staff so two surveys were carried out. One cohort had a WebCT quiz that contributed part of their assessment portfolio and survey questions were appended to this to ensure a high response rate. Another cohort undertook a paper survey of the module which included questions about the recordings. Table 2 shows numeric data

Table 2: Survey results Year 2.

\begin{tabular}{|l|c|c|c|c|c|}
\hline & Strongly Agree & Agree & Neutral & Disagree & Strongly Disagree \\
\hline $\begin{array}{l}\text { Having recordings of lectures } \\
\text { available is useful? }\end{array}$ & 13 & 23 & 11 & 2 & 1 \\
\hline $\begin{array}{l}\text { Streamed files were more } \\
\text { useful than MP3 files because it } \\
\text { made me set aside time to } \\
\text { listen? }\end{array}$ & 1 & 5 & 29 & 12 & 3 \\
\hline $\begin{array}{l}\text { I did not use the recordings } \\
\text { because they were streamed } \\
\text { but I would have done if they } \\
\text { had been available for } \\
\text { download? }\end{array}$ & 6 & 8 & 28 & 7 & 1 \\
\hline I accessed recordings & $>10$ times: 3 & $5-10$ times: 7 & $2-5$ times: 21 & Once: 9 & No access: 10 \\
\hline
\end{tabular}


What did you use recordings for? (WebCT survey)

\begin{tabular}{|l|}
\hline Checking on something that I didn't hear in the class \\
\hline Taking additional notes, going over something I didn't understand in class \\
\hline Missed lecture catch up, when the sheets were unclear you could hear Dr W explaining it \\
\hline I haven't used them yet but I will during my revision \\
\hline To check a missing piece of information \\
\hline Recapping the lecture, remind myself what some of the slide diagrams meant \\
\hline $\begin{array}{l}\text { For additional material which was not in lecture notes, to recap on what was said, sometimes its easier } \\
\text { to understand the lecture notes }\end{array}$ \\
\hline
\end{tabular}

Were the recordings a helpful resource? (Paper survey)

\begin{tabular}{|l|}
\hline I didn't use them but I like that they were there and you can use them to supplement your learning \\
\hline Yes, they help explain parts of the notes that were more complicated \\
\hline Very useful. Only problem I encountered was that outside the university it wasn't easy to access them \\
\hline Very useful. More lecturers should do this \\
\hline Definitely - anything extra is helpful \\
\hline The recordings were helpful, but not a substitute for the actual lectures \\
\hline I found them extremely helpful as I could listen to them in my own time and play back the important parts \\
\hline $\begin{array}{l}\text { I was at the lectures so didn't see a need to use them but I knew they were there if I needed to go over } \\
\text { any lectures again }\end{array}$ \\
\hline
\end{tabular}

on student attitudes, whilst Table 3 presents some of their comments. Over $70 \%$ agreed the recordings were useful and only $6 \%$ disagreed. Two opposing questions on the use of podcasts or streamed files suggest a slight preference for podcast, with $55-60 \%$ being neutral. There were no negative comments apart from some students saying they had not needed to use them, and a comment about accessibility off-site.

\section{Conclusions and Future Work}

The study shows that students will use audio recordings of live lectures and they find them to be beneficial. Data shows that uptake is typically $10-20 \%$ of the potential student-listenings (number of students times number of recordings), with a higher uptake in earlier years and when recordings are integrated into a supportive platform. Although this may seem a low return, very little effort was required to achieve this. Furthermore, not every student will want to listen to every recording.

There are issues to be considered with respect to recordings but a single source recording has benefits for control of distribution and editing. There are merits and disadvantages to both streaming and to podcasts, and whilst there is a slight preference for podcasts, there appears to be no strong preference amongst students thus allowing the lecturer freedom to choose what they consider most appropriate. Recording live lectures can require little additional effort by the academic.
Audio recording can find wider application, for example preparation of pre-lab materials, tutorial preparation, revision aids, and verbal feedback. These will require additional input compared with a live lecture, and therefore a prior evaluation should be made of alternatives such as video recording. However, audio recording has potential due to the ease of distribution and accessibility.

\section{Acknowledgements}

I am grateful for the students at the University of Abertay who have taken part in this study. The very helpful support of the staff of the Information Services department is also acknowledged 


\section{References}

1. H. M. Government, Special Educational Needs and Disability Act 2001, available from the Office of Public Sector Information, $<$ www.opsi.gov.uk/acts/acts2001/ ukpga_20010010_en_1> [accessed 24 May 2010].

2. The Higher Education Academy, Resources, Lecturing, available from <www.heacademy.ac.uk/resources/detail/ourwork/ internationalisation/ISL_Lecturing > [accessed 27 May 2010].

3. The Student room, How to Record Lectures, $1^{\text {st }}$ October 2008, available from $<$ www.thestudentroom.co.uk/showthread.php? $\mathrm{p}=14676365$ \#post14676365> [accessed 27 May 2010].

4. iPhone, Voice Memos, available on $<$ www.apple.com/uk/iphone/iphone-3g/voicememos.html> [accessed 24 May 2010].

5. Whatley, J. E., and Ahmad, A., (2007) Using Video to Record Summary Lectures to Aid Students' Revision, Interdisciplinary Journal of Knowledge and Learning Objective, 3, 185-196.

6. Bennet, E. and Maniar, N., Are Videoed Lectures an Effective Teaching Tool?, available from $<$ stream.port.ac.uk/papers/Are\%20videoed\%20lectures\% 20an\%20effective\%20teaching\%20tool.pdf> (Archived by WebCite® at <www.webcitation.org/5hNcigOCY> [accessed 24 May 2010].

7. Jarvis, C., and Dickie, J., (2009) Acknowledging the Forgotten and the 'Unknown'; The Role of Video Podcasts for Supporting Field-Based Learning, Planet, 22, 61-63.

8. The University of Northampton, Policy on electronic recording of lectures by students, <www2.northampton.ac.uk/portal/page/portal/ central_document_store/equality_and_diversity/ equality_and_diversity/37_5_procedural_development/ audio-record-policy.doc> [accessed 27 May 2010].

9. University of Aberdeen, Policy on permitting disabled students to audio-record lectures, <www.abdn.ac.uk/disability/tape-recording.shtml> [accessed 27 May 2010].

10. University of Cambridge, Agreement for the Recording of Lectures, $<$ www.admin.cam.ac.uk/univ/disability/loan/ recording.pdf> [accessed 27 May 2010]. 